\title{
Nature in the Active Voice ${ }^{1}$
}

\section{Val Plumwood}

\section{Need for a thorough rethink}

It seems increasingly possible that our immediate descendants, and perhaps many of those now living, will face the ultimate challenge of human viability: reversing our drive towards destroying our planetary habitat. Two important recent books, one by Jared Diamond (2005) and the other by Ronald Wright (2004), show how cultures that have been unable to change a bad ecological course have gone down. The appearance of ecological crises on the multiple fronts of energy, climate change and ecosystem degradation suggests we need much more than a narrow focus on energy substitutes. We need a thorough and open rethink which has the courage to question our most basic cultural narratives.

Imagine this scenario: The northern tribe of Easter Islanders never question the desperate religious cult that has devastated their section of the island as they try to placate with tree sacrifice the angry gods who withhold the rain. Instead, their leaders look around for new sources of trees, casting their eyes perhaps on the still-forested lands of the smaller tribe to the south. Meanwhile, their clever men, their scientists, are set to search for tree substitutes-other types of vegetation perhaps. But the need to consume the trees, given by the religion, is never questioned.

Most public discussion in our society is dominated by the tyranny of narrow focus and minimum rethink. A rethink deficit is a poor rational strategy in a situation where so many cracks are appearing in the empire, where multiple ecological problems are compounding and converging. Strategies that limit us to casting about for simple substitutes are dangerous. We revamp those hazardous sources good sense has led us to resist so far-nuclear fuels for example. Rethink deficit strategies do not encourage us to question the big framework narratives that underpin our extravagant demands or the associated commodity cult of economic growth. Or to question our right, as masters of the universe, to lay waste to the earth to maintain this cult's extreme lifestyle.

So, getting back to my case study, where could my putative Easter Islanders go to find intellectual help? In my scenario, science does what it is told by power, and scientists are not encouraged or intellectually equipped to address the bigger

\footnotetext{
${ }^{1}$ At the time this paper was written, Val Plumwood was a Visiting Fellow at the Centre for Resource and Environmental Studies (now the Fenner School of Environment and Society), Australian National University.
} 
questions. So the Islanders need more than science, and maybe a different kind of science. The Islanders of my scenario obviously need people with the courage to look about them and speak up for change. They need ecological knowledge and memory to help them recognise how nature supports their lives. Most crucially, they also need people who can open their culture to self-criticism, make them think harder about their big assumptions, such as their high-consumption religion, and its suitability for their very limited support context.

Perhaps what my Easter Islanders need is a college of philosophers, backed up by a full choir from the humanities? Supposedly, the subject area with the brief for the full rethink is philosophy, whose best traditions have claimed to hold everything open to question. As a feminist philosopher, I would say that philosophy does not always live up to these ideals, and itself has a significant self-reflection deficit. Much of it is far too uncritical of the canon, to which I myself feel very little loyalty. (My own allegiance is to certain kinds of philosophical argument and methods but not to the canon.)

Obviously philosophy with an excessive respect for tradition won't help the Islanders' rethink problem. They might get help though from the more radical strand of philosophy that, in Foucault's words, 'endeavour[s] to know how and to what extent it might be possible to think differently, instead of legitimating what is already known' (8-9). Could the recent area of environmental philosophy help the Islanders to 'think differently' about the dogmas that are ruining their island?

\section{Environmental philosophy}

First appearing in academia in the area of value theory in the early 1970s, environmental philosophy has now made itself felt across the whole discipline of philosophy, taking in core areas such as political philosophy, justice ethics, history of philosophy, moral epistemology and metaphysics. In all these areas philosophers have exposed the dangerous logic of current frameworks that devalue and background the non-human world. Some have argued that our human-centredness weaves a dangerous set of illusions about the human condition right into the logic of our basic conceptual structures (see Plumwood, Environmental Culture).

Environmental philosophy remains marginal, many would say, in academia. ${ }^{2}$ There have been some great recent contributions to environmental philosophy (for example Mathews, For Love of Matter; Reinhabiting Reality) but my overall

\footnotetext{
2 I'm not happy about confining the term 'philosophy' to academic or written philosophy, as some want to do. Arguably environmental philosophy is not just a recent academic invention but at the heart of the life practice of indigenous people in Australia for whom relations with the land were at the centre, not the margin of life.
} 
assessment from over thirty years of involvement is that the discipline needs re-commitment and renewal, and presently is not sufficiently addressing our planetary ecological crisis or providing us with adequate guidance. (Perhaps the increasing influence of money in our learning systems would help explain why this area has been neglected.) Certainly environmental philosophy no longer holds the premier place it held in the 1970s and 80s among non-science disciplines. In Australia, the area has faced neglect or outright hostility from conventional philosophy, and has receded. In the humanities, the baton has been picked up by emerging stars-eco-politics, eco-anthropology and eco-criticism in literature. I'll have more to say about their important contributions later. ${ }^{3}$ Is this a race against time to remake the culture? You wouldn't think so from the low priority of these areas in the humanities and in philosophy programs and discussion.

Perhaps one reason the Easter Islanders may not get much guidance from environmental philosophy is because the college has been conventionally divided since the early 70s into the shallow and the deep sections, depending on whether their concern is with humans or non-humans. Australian environmental philosophers have contributed in a major way on both sides. John Passmore argued in 1974 for the adequacy of a 'humans only' tradition, and was balanced by local theorists from the same period on the deep side. Deep Ecology and Deep Green Theory were major brand names that emerged in the 70s. Themes of respect for nature, critiques of human arrogance and human-centredness, debates about intrinsic and instrumental value appeared in 1970s papers. Deeps focused on a better deal for non-humans - with other human-oriented ecological issues counted as shallow. ${ }^{4}$ Many argued for an expansion of ethics to non-humans, or for their inclusion in a larger ethical community, with very different views about how to constitute it. People like Peter Singer (Animal Liberation) wanted to extend the ethical community minimally to those most like humans (certain animals), while others, including myself, wanted a much larger, less humanised community, with an ethic of respect and attention needing no stopping point.

On the other, 'shallower' wing, philosophers like Passmore argued that a position considering only human interests would be enough to get us by, that it is

\footnotetext{
3 The emerging transdisciplinary area of the ecohumanities has some important contributions to environmental thought, but also some problematic ones, the latter emerging especially from forms of postmodernism. Indeed, the humanities harbours its own forms of reductionism and idealism about nature that maintain human self-enclosure and hinder the rethink. For example, a major recent humanities preoccupation has been developing idealist concepts and arguments that reject all concepts of nature as presenting limits and treat nature as a human construction. These sorts of positions are unlikely to help the Easter Islanders come to terms with their major problem of recognising how nature supports their lives. For a critique of these tendencies, see Val Plumwood 'Towards a Progressive Naturalism'; 'The Concept of a Cultural Landscape'.

${ }^{4}$ Major cultural shifts were required. Many studies supported the idea that the past and present lives of Indigenous people showed what could be done in the way of decreasing demands, living less conflictually with nature and giving respect to the natural world (contraction and convergence strategy).
} 
dangerous to question human supremacy; they advocated minimum rethink-a cleverer instrumentalism was needed. Non-human harm only matters when humans suffer too. I would argue against this minimising rationality of instrumentalism that genuinely sustainable systems cannot be ones that allocate merely minimum resources for providers' survival, as egoist economic rationality currently dictates. They must encourage greater levels of consideration for providers' long-term well-being. This rules out instrumental, servant or slave-like relations as well as competitive market relations (to name a few of those that encourage us to cut costs at the provider's expense), and rules in mutualistic forms of rationality.

This is why I think the conventional deep/shallow division is a pernicious false choice. A rigid division that makes us choose between human and non-human sides precludes a critical cultural focus on problems of human ecological identity and relationship, and is also bad for activism. It assumes a fallacious choice of self/other, taking an us-versus-them approach in which concern is contaminated by self-interest unless it is purely concern for the other. Most issues and motivations are double-sided, mixed, combining self/other, human and non-human interests, and it is not only possible but essential to take account of both. Both kinds of concerns must be mobilised and related.

Philosophy, I think, must understand humans as immersed in a medium that is both deep and shallow (although not in the same place). Our shift into a mixed framework enables us to see that human-centredness can have severe costs for humans as well as non-humans. Global warming is a case in point. Humans will lose, and so will non-humans. I think a more promising approach is to redefine what is 'deep' as that which challenges human-centredness. Then we can address both kinds of issues, human and non-human, in a deep way. Human-centredness is a complex syndrome which includes the hyperseraparation of humans as a special species and the reduction of non-humans to their usefulness to humans, or instrumentalism. Many have claimed that this is the only prudent, rational or possible course.

I argue contrary to this that human-centredness is not in the interests of either humans or non-humans, that it is even dangerous and irrational. ${ }^{5}$ My argument is that one of its results is a failure to understand our embeddedness in and dependency on nature, that it distorts our perceptions and enframings in ways that make us insensitive to limits, dependencies and interconnections of a non-human kind. Where mind is taken as coincident with the human, hyperseparation is expressed in denying both the mind-like aspects of nature

\footnotetext{
${ }^{5}$ Our shift in framework enables us to see that human-centredness can have severe costs for humans as well as non-humans. Under the old criterion of depth, in which consideration of costs to humans is inevitably 'shallow', it is not possible to consistently raise the question of how far human-centredness is a disadvantage to humans themselves.
} 
and the nature-like aspects of the human: for example, human immersion in and dependency on an ecological world. When we hyperseparate ourselves from nature and reduce it conceptually, we not only lose the ability to empathise and to see the non-human sphere in ethical terms, but also get a false sense of our own character and location that includes an illusory sense of agency and autonomy. So human-centred conceptual frameworks are a direct hazard to non-humans, but are also an indirect prudential hazard to Self, to humans, especially in a situation where we press limits.

This is one of many places where insights drawn from feminist theory can be helpful. Male-centredness (a good parallel in some ways to human-centredness) can be damaging to men as well as to women. It makes men insensitive to dependencies as interconnections, as well as devaluing women. It has to be tackled from many sides, by changing men and by changing women, changing individuals and changing institutions. Human-centredness is similarly double-sided, and we have to see the denial of our own embodiment, animality and inclusion in the natural order as the other side of our distancing from and devaluation of that order. Human-centred culture damages our ability to see ourselves as part of ecosystems and understand how nature supports our lives. So the resulting delusions of being ecologically invulnerable, beyond animality and 'outside nature' lead to the failure to understand our ecological identities and dependencies on nature.

This failure lies behind many environmental catastrophes, both human and non-human. The inability or refusal to recognise the way non-humans contribute to or support our lives encourages us to starve them of resources. It has justice aspects because we refuse to give other species their share of the earth, and it has ethical aspects because we fail them in care, consideration and attention. This means that our 'deep' human-centred ethical failures and our 'shallow' prudential failures are closely and interactively linked.

\section{Nuclear power}

A corollary is that a deep analysis that challenges human-centredness can have much to say to human sustainability. The deep aspects come from the need to see ourselves as more limited beings, constrained by the ecological needs of the larger biospheric community. There is definitely a deep side to the energy and climate issues, although we don't hear much about it.

A classic example is nuclear power. There are major concerns about human welfare, but the issue definitely has a deep side, both in terms of ecojustice for non-human lives and systems, and in terms of technological overconfidence and the approach to risks and limits. I think the illusion of ecological invulnerability appears in the way advocates of nuclear power fail to imagine or take seriously its enormous ecological risks and costs - the risks of storing radioactive wastes 
for up to half a million years, for example, and the enormous risks involved in transport and storage.

We get nuclear instead of rethink. Nuclear advocates would inflict a horrendous burden of waste disposal and other risks on many future generations of humans and non-humans, none of whom will benefit or be consulted (see Routley \& Plumwood, 'Nuclear Energy'; 'Ethics of Nuclear Power'). Why? So we can put off the inevitable rethink for another fifty years and continue the energy extravaganza that derives from seeing ourselves as masters of the universe. The deep aspect of climate and energy issues is the need to rethink ourselves as more limited and responsible beings in the biosphere. This also implies rejecting technologies that demand future human invulnerability and perfection, such as perfectionist forms of nuclear and genetic tinkering.

\section{Reductionism and human/nature dualism}

Contemporary human societies seem to have many similar problems to the Easter Islanders: failure to understand our ecological situation, being out of touch with what is happening to our ecological world and with ourselves as ecological beings. Can environmental philosophy perhaps help us understand how we got into this situation? I think it can. We need to understand the history and the logic of some key concepts to see how the trap we are in has been put together. Then there is a chance we might work out how to get out of it - although, sadly, causative insight provides no guarantee of escape.

The hyperbolised opposition between humans and the non-human order I call human/nature dualism is a western-based cultural formation going back thousands of years that sees the essentially human as part of a radically separate order of reason, mind, or consciousness, set apart from the lower order that comprises the body, the woman, the animal and the pre-human (see Lloyd; Plumwood, Feminism). Human/nature dualism conceives the human as not only superior to but as different in kind from the non-human, which is conceived as a lower non-conscious and non-communicative purely physical sphere that exists as a mere resource or instrument for the higher human one. The human essence is not the ecologically-embodied 'animal' side of self, which is best neglected, but the higher disembodied element of mind, reason, culture and soul or spirit.

The other side of this is the reduction of nature that is part of the dualist formation. On the one side of this hyperseparation, we set ourselves sharply apart from everything else as essentially mindful beings. On the other side we get the concept of nature as dead matter, all elements of mind and intelligence having been contracted to the human. The idea of nature as dead matter, to which some separate driver has to add life, organization, intelligence and design, is part of human/nature dualism. 
This ideology of dualism and human apartness can be traced down through western culture through Christianity and modern science. With the enlightenment, human apartness is consolidated and augmented by a very strong form of reductionist materialism, whose project, in Descartes' formulation, is 'the empire of man over mere things'. This framework identifies mind with consciousness, solidarises the human species as uniquely conscious agents, and reduces non-human forms to 'mere matter', emptied of agency, spirit and intelligence. Reductive concepts that restrict even the vocabulary of mindfulness and moral sensibility to humans naturalise the treatment of non-humans as slaves or mere tools-making it seem natural that they are available for our unconstrained use and are reduced to that use (are 'resources').

Reductionism, as an important cultural development associated with modernity, actually relies on a reified separation that took place a lot earlier, through a process of splitting and a hegemonic construction of agency and identity. According to a typical hegemonic pattern, the most general form of mind/body dualism, matter itself (chaos) is not creative, but is silent and formless. Being is split into an uncreative, featureless material part and a hyperseparate, externalised and often dematerialised 'director' or 'driver', usually intelligence, mind or reason, on the other side. The 'driver' is the real author of change, as a separate mechanism or intelligence driving the materially-reduced organism from outside, and it is to this external driver that true agency and respect is attributed. Plato plays this out in the Timaeus with cosmos (rational principle) as driver of chaos - itself prior, formless, empty and inchoate matter.

It is important to understand how the reductive materialism that defines modernity derives from this older construction that splits mind from matter and devalues the material. It is not a bold new beginning, launching out into the void in an explosion of brave new rationality. It simply affirms universally one side of this older dualism, denying the spirit side of the original dualism completely or confining it to humans (or gods). That is, the reductionist materialism that is regarded as the new beginning to modernity is actually just a truncated dualism which preserves at its heart the original splitting and reducing process, stripping mind, intelligence and agency out of materiality and awarding it to a separate driver. It represents nature as passive and uncreative, real creativity coming only from (various) mind-identified drivers, usually humans or humanoid. Modernity's philosophical contribution so understood is less impressive: a contribution that kills off the driver without questioning the reduced concept of materiality that was its other side. This truncated dualism is what underpins the empire of man over mere things, what propels its commodity spirituality. ${ }^{6}$

\footnotetext{
${ }^{6}$ I argued the case that reductive materialism was a truncated dualism in Feminism and the Mastery of Nature. This analysis also explains why it is a mistake to locate the entire problem in modernity, as
} 
Modernist reductionism is highly relevant to the ecological crisis. This ideology has been functional for western culture in enabling it to colonise and exploit the non-human world and so-called 'primitive' cultures with less constraint. But it also inherits the dangerous illusions that deny human embeddedness in and dependency on nature. It generates modernity's dominant narratives of scientific progress, unconstrained commodity culture and unlimited growth. By consolidating the narratives of the empire of man over mere things, reductionist rationality removes key constraints at the dawn of commoditisation and capitalism. This is no coincidence of course. I think we do have to understand philosophy in social terms, not as a collection of individual philosophical ideas.

\section{Science consolidates the empire}

Science is crucial in consolidating the Empire of Man over Mere Things. In the new scientific fantasy of mastery, the new human task becomes that of remoulding nature to conform to the dictates of reason to achieve salvation-here on earth rather than in heaven - as freedom from death and bodily limitation. The idea of human apartness emphasised in culture, religion and science was, of course, shockingly challenged by Charles Darwin in his argument that humans evolved from non-human species. But these limited insights of continuity and kinship with other life forms (the real scandal of Darwin's thought) remain only superficially absorbed in the dominant culture, even by scientists. The traditional scientific project of technological control is justified by continuing to think of humans as a special superior species, set apart and entitled to manipulate and commodify the earth and other species for their own exclusive benefit.

This world is conceived as an aggregation of material objects, meaningless in themselves and only given meaning or form by their driver. This has been called 'the death of nature' (Merchant). The organismic idea of nature as a realm of creative and self-organising systems has to be killed off by capitalism/reductionism because nature in the active and intelligent voice cannot so easily be backgrounded, appropriated and destroyed for human gain. Scientific reductionism assumes a mindless meaningless materialist universe open to endless unrestricted manipulation and appropriation: nature is the suppressed slave collaborator - a mere resource, or transparent enabler of projects. ${ }^{7}$

Now most modern philosophy has supported this materialist reductionism in the name of defending 'hard-headed' scientific rationality. Australian philosophers, many operating under the rather misleading label 'empiricism', 8 have been in the lead, insisting that no other rational possibilities exist.

many green thinkers do. I think we must go further back and draw in an older range of positions, such as monotheism. This means that the crucial development marking modernity is not the loss of Christianity or some other monotheistic faith, but the adoption of such a secondary reductionism.

7 On the knowledge model involved here, see Plumwood Environmental Culture, chapter 2.

8 And behind them stand many other English-speaking philosophers. 
Alternatives are debunked as involving superstition and primitivism, even animism, in contrast to science and rationality. I think it is a serious mistake to identify science and rationality with materialist reductionism. More respectful forms of science are not only possible but are better forms of rationality.

This minimising rationality makes the least of the non-human other; it is not materialism in the sense that it respects the material order or works generally in its favour, and in my view it should not really be called 'materialism' at all. Of course, some materialist philosophers concede that often it is a better predictive assumption to think as if there were some mindfulness to the non-human world (what Dennett calls the 'intentional stance' (Intentional Stance; Kinds of Minds)), but they add that we don't really have to take that mindfulness seriously - it's all just a metaphor! This way we can preserve the exploitation benefits of reduction without all the costs of sacrificing knowledge and order. As a Philosophical Animist, I argue that this is doublethink, and that we do have to take the intentional stance quite seriously for non-humans. ${ }^{9}$ We will lose the justification for empire - an empire of growing human, cultural and biological poverty - but can open another door to a richer world, and can begin to negotiate life membership in an ecological community of kindred beings. This is a better rationality.

\section{Creationism}

This analysis casts the contemporary position known as creationism in an interesting new light. I see creationists as affirming the original reductionist split that deprived nature of creative power, meaning and mind. Creationists say things like:

I'm not a mere accident.

I am not 'a cosmic accident of a chaotic medium'.

I am not just a 'fluke of nature'.

I'm a product of unnatural selection, not natural selection, the product of a designer, a creator.

I'm not the descendant of apes. I was put here by a designer.

It [nature] couldn't have got there by itself. It needed a designer.

Several interesting things are happening here: an insistence on human apartness, and an insistence on nature's blindness and lack of mind. Apartness forces creationists to deny the fluidity of the human that the evolution story requires, its flowing on into the non-human, both at death, and in historical, evolutionary terms from non-human as well as human ancestors. The Creationist Museum in Kentucky, for example, denies the existence of 'missing link' fossils, asserting

\footnotetext{
9 See my argument in Plumwood Environmental Culture, chapter 8.
} 
that humans have always been as they are now. Supposed 'missing links' are actually deformed people (see Bates).

It is clear that in rejecting the 'random selection' of evolution and calling for a designer, creationists are affirming the very same reduced concept of material order as 'mere things' posited by reductive materialism. Nature is an accidental, chaotic and basically meaningless sphere lacking genuine creativity. In this impoverished creation narrative, mere things have no creativity, only an external designer can have it. Creationists are endorsing the reductionist, debased, 'mere matter' concept of nature supplied by reductive science, following in the Platonic footsteps. Creationism is about re-affirming human apartness and the reduced concept of matter associated with it (including the mind/matter split), together with a project to reinstate the original driver/father, or something very like him. ${ }^{10}$

Creationists distance themselves from the meaningless 'mere things' they see science as revealing, as well as expressing the faith that the missing meaning will be returned by an all-powerful creator in the future paradise to come. Creationism is very much a reassertion of human apartness, plus the assimilation of the world of nature to the mindless and meaningless sphere left after the external driver is done away with. Nature - portrayed as random, heartless and lacking - is reduced to mere accident, a chaotic sphere evolving through blind chance and meaningless accident, and thus incapable by itself of delivering the culmination of history - the human mind, as uniquely exhibited in our own species! Meaning, intelligence and communicativity belong to the external driver, who is to be found only in the human or humanoid sphere (see Plumwood, Feminism 110). At bottom creationism buys the very same reduced framework as reductive materialism. We can see contemporary creationism as a reaction to and as conceptually parasitic on reductionism.

Of course creationists are right in wanting to reject the meaningless universe, but wrong in endorsing the driver/materiality split or in demanding restoration of the original defunct driver. Both positions are guilty of the same fault of denying and suppressing nature's own mindfulness and creativity. Science has been busy generating wondrous narratives (usually told by the scientific community in very inhibited, mind-evacuated vocabularies, and in mutually-censoring ways) about this self-creativity (see Noble). These narratives are usually much richer and more attentive to the world around us than the simplistic patriarchal narratives of the Creationists in which the world is the recent invention of a humanoid god.

\footnotetext{
10 The parallel here is an Aristotelian-style theory of reproduction, involving the suppression of the female party and the promotion of father as true creator. (Suppression means use plus denial.) The narrative that underpins these concerns links women, nature and materiality.
} 
But science is severely hampered in countering the creationist worldview, and in representing and celebrating the creativity of nature it discloses, by its traditional identification of rationality with reductive materialism. In a way, reductive forms of science have themselves to blame for creationism. A sufficiently stripped-down, dualised machine nature demands an external, anthroform designer. So reductionist science has helped produce the demand for a designer through its own mistaken reductionist and mechanistic stance.

So to the creationist, the Philosophical Animist would say: Your story of creation is really impoverished compared to the incredible, infinite complexity of the real earth story written in the rocks and in the bodies of living things, species diversity and evolution. Without the draining out of spirit and creativity from matter and its centralisation in your god figure, we have creative, active and mindful matter all around us. ${ }^{11}$ In an intentional universe we can have it both ways, a dispersed creativity and a decentralised intentionality. For this, we need to spread concepts of agency and creativity more widely into what we have thought of as the dead world of nature.

\section{Thinking differently}

So reductionism (reductive materialism) represents a very incomplete rejection of the original spirit/matter dualist framework. A genuine rejection would be an enriched materialism that puts back the mindful and creative properties that had been stripped out and handed over to the defunct driver. However, the debate usually assumes a false choice of reductive materialism versus creationism, with conventional science calling on us to defend the extreme reductionism and human hyperseparation that it so wrongly identifies with rationality.

The debate has assumed a false choice of creativity as the prerogative of the pinpoint agency of a singularised creator, versus creativity as confined to the human knower (culture) and stripped from non-agentic nature. The real alternatives are not creationism versus reductionism, but creationism/reductionism versus animism (as enriched materialism), where

\footnotetext{
11 Monotheisms have much to answer for here too. Monotheisms have long aimed to expel the creative from all but their chosen pinpoint of reverence, and they have been able to conspire together to represent this as the normal orientation of religions. Creationist theory posits god as an external creator concentrated into a single, minimum point of intentionality and agency, a personally-responsive mind who can provide salvation from the mortal estate if properly invoked or placated. But many so-called 'primitive religions', as Vine Deloria (127) points out, have been profoundly different in acknowledging revelations of the sacred as appearing at many points and in diverse spheres. Further, according to Deloria, 'The eastern stream in which Buddhism, Taoism and Confucianism interact develops from forms of animism to the idea of a cosmic order, a way of balance and harmony following which brings stability and calm of mind, and peace and right order in society. In this stream, there is little stress on one Absolute being or God.' 'Hinduism, Buddhism and Shintoism lack one other distinction so fundamental for our Christian thinking: the belief in the basic essential difference between creation and Creator' (129 quoting Ernest Benz). ... 'Why the compulsive separation, which so many panentheist theologians have rejected? Why not be satisfied with saying: the world makes sense to us and we can operate safely within its rhythms' (130).
} 
animism would spread mind and creativity out much more widely. That the opportunity is available philosophically to do this via openness to the intentionality of the world I argued in my 1993 book, Feminism and the Mastery of Nature. Monopolising mind may make us feel superior but it is not helping our accommodation to the earth.

An animist materialism has a different answer to creationism than reductive materialism identified with science (which really doesn't have an answer at all except self-promotion). It advises science to re-envisage materiality in richer terms that escape the spirit/matter and mind/matter dualisms involved in creationism. Forget the passive machine model and tell us more about the self-inventive and self-elaborative capacity of nature, about the intentionality of the non-human world. If the other-than-human world has such capacities, we don't need an external designer to put them in. It is its own designer, to the extent that design is in question.

Recent work in ecoanthropology supports this possibility for thinking differently. It finds that many indigenous cultures have much more animated, agentic and intentional views of the world of nature. Writers such as Graham Harvey, Tim Ingold and Deborah Bird Rose have shown how our concepts of rationality have misunderstood and misrepresented indigenous animism in our own dualistic terms. Colonial ethnocentrism saw 'animism' as holding that humanoid (often demonic) spirits inhabit and animate material objects as separate drivers, which could be welcomed, influenced or evicted. This ploy enabled them to read our own dualisms back into other cultures, and thus to present this major alternative to reductionism as primitive and anti-rational. In this way they were heading off the possibility of anyone (at least anyone rational) being able to think differently.

So the big question is: Can we think differently? Can what has been stripped out of our conception of the material world be put back? Can we begin to entertain the hypothesis that the world of nature around us may have many of the intelligent and creative powers the splitters hive off to the designer? Suppose that instead of splitting and denigrating the intelligence of the non-human world and attributing creation to an external deity or driver, we began to try to see creativity and agency in the other-than-human world around us. Although it helps to reveal the wondrous creativity of life, science has been doing an ambiguous job in conveying this message of evolutionary theory, because of its ideological commitment to reductionism and its mistaken identification of this narrow and human-centred outlook with rationality.

We need to rethink concepts of meaning and accident in relation to the non-human world, and to question the reductive and human-centred frameworks that depict places in nature, often rich in narrative, as the product of meaningless coincidence. Ancient places like the Stone Country of Arnhem Land confront 
us sharply with the difficult knowledge of our own limitations as knowers, for in the complex and intricate narrative that explains the emergence of the correspondingly complex and intricate stone forms we see around us, we can as human observers never know a full story that matches the intricacy we observe. We can discern only a few of its broader outlines: that these extraordinary formations have evolved through the ancestral processes of sea, rain and wind that have sculpted them through deep tides of time. To save face, our instrumental culture conveniently dismisses the rest under the rubric of coincidence, contingency, accident, or formless chaos, belittling all complexities we cannot know or control.

Thinking differently is (in part) about recognising creativity and intelligence in nature and in evolution. Why can't we see evolution, for example, as a form of experimentation, of testing and learning, like trial and error, a form of wisdom? Why can we not consider evolution as a demonstration of mind in nature, of the intelligence involved in species differentiation and elaboration, the intelligence of forms, 'the wisdom in the wing' (Dennett, Kinds of Minds) in the form of the species body and its adaptation (via species difference and elaboration) to a particular creative ecological niche via a process of evolutionary learning? Dispersing creativity and agency, we can think the possibility of creative, mindful matter. We don't need to make the choice between materiality and meaning the creationists create.

Philosophical alternatives that discern wisdom and intelligence in the material world can help move us from the monological to the dialogical, from domination to negotiation with our very material ecological context. They make possible respect and renarrativisation, as ways to combat the regime of anonymous commodities, and have an important role to play in reducing overconsumption. We need new origin stories that can disrupt the commodity regimes that produce anonymity by erasing narratives of material origins and labour, and replacing them by narcissistic dreams of consumer desire and endless, consequenceless consumption and growth.

\section{The Role of Writing}

The enriching, intentionalising and animating project I have championed is also a project that converges with much poetry and literature. It is a project of re-animating the world, and remaking ourselves as well, so as to become multiply enriched but consequently constrained members of an ecological community. Opportunities for re-animating matter include making room for seeing much of what has been presented as meaningless accident actually as creative non-human agency. In re-animating, we become open to hearing sound as voice, seeing movement as action, adaptation as intelligence and dialogue, coincidence and chaos as the creativity of matter. The difference here is intentionality, the ability 
to use an intentional vocabulary. Above all, it is permission to depict nature in the active voice, the domain of agency.

The path has a mind of its own but a body shared by hundreds. It is a way through the woods, a way made by the five-toes, the four-toes, the cloven hooves and a few big clodhoppers like mine. This is a path with a memory, a remembrance of passings, and it offers itself to the future for those who recognize a way worth taking. A raven rasps its rapid cries into a strong, south-westerly wind, which rakes through treetops of ash, small-leaved lime, beech and oak. In holly thickets the wind stirs goldcrests and they sing like jingling pockets of change. Old hulks of crashed elm speak of an older wood. When they were alive, a track to take out timber and charcoal cut across the slope. The elms are long fallen and so are the woodsmen whose ghost road leads nowhere. The path only slides down the steep bank to glance along old fragments of the track and then swerves back into the trees, as if deciding it a bit too unsafe to follow the abandoned way.

The path touches on the history of the hedge bank too: its mound and ditches perhaps medieval, maybe older, are also under lost trees that have shaken loose of the hedge and risen $15 \mathrm{~m}$ into the air. And above them a pair of crows play in the updraught, tumbling through the wind, snapping at the strings of their own ways through the sky. Midway, between the canopy and the ground, a hard whirring sound: a hornet, slow in the cool air, finds its hole in the hollow lime trees and closes itself into the darkness there. On the narrow, wandering line below, gouged out of clay by hoof, pad, claw and the occasional boot, I follow-a passing thought.

(Evans 22)

Notice that in this passage there are many active, agentic subjects, which give the passage its life. Every sentence except one is in the active voice, and all involve intentionality. Although none of these subjects is human, we can all understand the passage quite well, and it does not cultivate the gothic or strike one as outlandish. I think most of us would find it beautiful.

Writers are amongst the foremost of those who can help us to think differently. Of course, artistic integrity, honesty and truthfulness to experience are crucial in any re-discovery of 'tongues in trees'. I am not talking about inventing fairies at the bottom of the garden. It's a matter of being open to experiences of nature as powerful, agentic and creative, making space in our culture for an animating sensibility and vocabulary.

But there are certain critical concepts that are used to stop us thinking differently, that are used in inhibiting and delegitimating any new or old animating 
sensibility. The concept of anthropomorphism, of 'presenting non-humans illegitimately as more like humans than they really are' plays a major role here. This charge of anthropomorphism is often invoked when someone is found guilty of presenting the non-human world in more agentic and intentional terms than reductionism allows.

Anthropomorphism is a very tricky concept, with many functions. But one of its main recent roles is that of policeman for reductive materialism, enforcing polarised and segregated vocabularies for humans and non-humans. Its covert assumption is usually the Cartesian one that mentalistic qualities are confined to the human, and that no mentalistic terms can properly be used for the non-human. Attempts to apply intentional terms for the non-human can then be said to involve presenting them in unduly human-like terms.

For example, in reviewing the recent movie about king penguins The March of the Penguins, many critics took particular exception to the film's intentional description, to the idea that the king penguins could be said to 'love' one another. In terms of the cluster of behavioural criteria for applying the term 'love', such as being willing to suffer in major ways for the loved one, the application of the term to the penguins seems well warranted. True, penguin lovers may move on next breeding season, but why require permanence? A high redefinition of love as lasting forever would certainly rule out most human loves.

Of course this charge of anthropomorphism completely begs the question of non-human minds. That has become its major function now, to bully people out of 'thinking differently'. It is such a highly abused concept, one often used carelessly and uncritically to allow us to avoid the hard work of scrutinising or revealing our assumptions, that there is a good case for dropping the term completely. ${ }^{12}$ Stop hiding behind that wall of Greek, and try saying what you mean in simple direct language! If your thesis is to be stated as: 'This film/book presents non-humans as much more like humans than they really are', be prepared to be asked: 'In what respect'? If your reply is: 'Only humans can have minds, or the capacity to love', be prepared to defend this indefensible claim, which is now out there in the open for all to see and engage in counter-arguments with.

Otherwise, my advice is: Free up your mind, and make your own contributions to the project of disrupting reductionism and mechanism. Help us re-imagine the world in richer terms that will allow us to find ourselves in dialogue with and limited by other species' needs, other kinds of minds. I'm not going to try to tell you how to do it. There are many ways to do it. But I hope I have

\footnotetext{
12 I believe there are some valid uses of the term, such as pointing to failures to respect non-human difference, but these uses are now so enmeshed with the problematic ones that they are best stated in other terms. For a more extended discussion of the concept, see Plumwood Environmental Culture, chapter 2 .
} 
convinced you that this is not a dilettante project. The struggle to think differently, to remake our reductionist culture, is a basic survival project in our present context. I hope you will join it.

Val Plumwood (1939-2008) was a founding intellectual and activist in the global movement that came to be known as ecofeminism. She published three major books as well as over a hundred articles and encyclopaedia entries, and her work has been translated into numerous languages. In February 2008 she died of a stroke at her home in the bush, aged sixty-eight.

\section{Works Cited}

Bates, Stephen. 'Bones of Contention'. Guardian Weekly 24 November 2006: 20.

Deloria, Vine. Evolution, Creationism \& Other Modern Myths: A Critical Inquiry. Golden, CO: Fulcrum Publishing, 2002.

Dennett, D.C. The Intentional Stance. Cambridge MA: MIT Press, 1989.

—. Kinds of Minds. London: Weidenfeld and Nicholson, 1996.

Diamond, Jared. Collapse: How Societies Choose to Fail or Succeed. New York: Viking Press, 2005.

Evans, Paul. 'Down Memory Lane'. Guardian Weekly 24 November 2006: 22.

Foucault, Michel. The Use of Pleasure (Vol 2 of The History of Sexuality). New York: Vintage Books, 1986.

Harvey, Graham. Animism: Respecting the Living World. New York: Columbia UP, 2006.

Ingold, Tim. The Perception of the Environment. Essays in Livelihood, Dwelling and Skill. London: Routledge, 2000.

Lloyd, Genevieve. The Man of Reason: 'Male' and 'Female' in Western Philosophy. Minneapolis: U of Minnesota P, 1984.

Mathews, Freya. For Love of Matter: A Contemporary Panpsychism. New York: SUNY, 2003.

—. Reinhabiting Reality: Towards a Recovery of Culture. New York: SUNY, 2005.

Merchant, Carolyn. The Death of Nature: Women, Ecology and the Scientific Revolution. London: Wildwood House, 1980.

Noble, Denis. The Music of Life. Oxford: Oxford UP, 2006.

Plumwood, Val. 'The Concept of a Cultural Landscape.' Ethics and the Environment 11.2 (2006): 115-50. 
-. Environmental Culture: The Ecological Crisis of Reason. London: Routledge, 2002.

- Feminism and the Mastery of Nature. London: Routledge, 1993.

- 'Towards a Progressive Naturalism.' Recognizing the Autonomy of Nature. Ed. T. Heyd. New York: Columbia UP, 2005. 25-53.

Rose, Deborah. Reports from a Wild Country Sydney: U of New South Wales P, 2004.

Routley, Richard and Val Plumwood. 'Nuclear Energy and Obligations to the Future.' Responsibilities to future generations: environmental ethics. Ed. E. Partridge. Buffalo, NY: Prometheus Books, 1980.

Routley, Richard and Val Plumwood. 'The Ethics of Nuclear Power.' And Justice For All. Ed. D. Van Der Veer and T. Regan. Totowa, N.J.: Rowman and Littlefield, 1982. Reprinted in Peg Tittle, ed. Ethical Issues in Business. Ontario CA: Broadview Press, 2000.

Singer, Peter. Animal Liberation: A New Ethics for our Treatment of Animals. New York: New York Review/Random House, 1975.

Wright, Ronald. A Short History of Progress. Melbourne: Text, 2005. 